\title{
Maggots at colostomy site: an unusual finding!
}

\section{Shramya Shodhan Kumar, Bharath Veerabhadrappa, Afroz Khan, Gabriel Sunil Rodrigues}

Kasturba Medical College, Manipal Academy of Higher Education, Manipal, India

A 77-year-old male patient who had undergone sigmoid colostomy for acute intestinal obstruction secondary to rectal infiltration by an advanced, inoperable prostate carcinoma presented to emergency with complaints of pain at the colostomy site. Local examination revealed the presence of maggots, an edematous stoma that was patent, discharging normal stools, and surrounding skin excoriation (Fig. 1). Turpentine oil was applied and the maggots were removed. Glycerin/magnesium sulfate was applied over the stoma to reduce mucosal edema with a good response (Fig. 2). The patient and his primary caretaker were taught and advised regarding colostomy care.

Maggots (fly larvae) over limb ulcers (diabetic/venous) are a common entity that can be attributed to poor hygiene, living conditions, negligence and a lack of education in developing countries. Treatment involves turpentine oil application, debridement and regular dressings [1]. Though it is not "a pleasant sight" to have maggots on one's body part, they have been known to be capable of naturally removing slough and necrotic tissue and are hence useful in the debridement of non-healing ulcers [2]. The use of live, disinfected maggots over non-healing ulcers is known as maggot debridement therapy (MDT) for debridement and disinfection; its efficacy continues to be debatable. MDT removes the devitalized tissue effectively with minimal tissue trauma and has been utilized with varying success rates ranging from around 80$90 \%[1-3]$.

Maggots at the colostomy site represent a rare entity, one that has not been reported in the literature so far and is mainly secondary to poor compliance, as in our patient. This can be prevented by preoperative counseling and educating the patient and the patient's caretakers prior to discharge regarding skin and colostomy care.

Department of General Surgery, Kasturba Medical College, Manipal Academy of Higher Education, Manipal, India

\section{Conflict of Interest: None}

Correspondence to: Gabriel Sunil Rodrigues, MS, DNB, FRCS (Glasg), Professor, General Surgery, Kasturba Medical College, Manipal Academy of Higher Education, Manipal 576104, India, e-mail: gabyrodricks@gmail.com

Received 21 July 2018; accepted 29 July 2018; published online 24 September 2018

DOI: https://doi.org/10.20524/aog.2018.0312

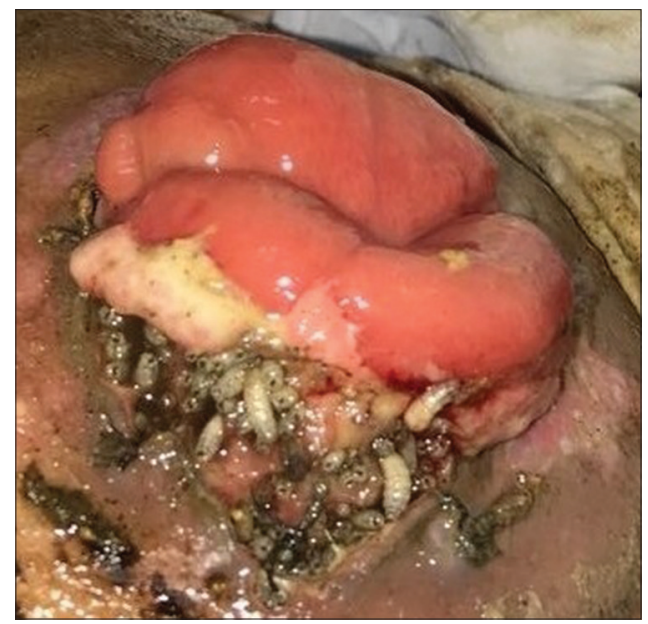

Figure 1 Edematous colostomy site with maggots

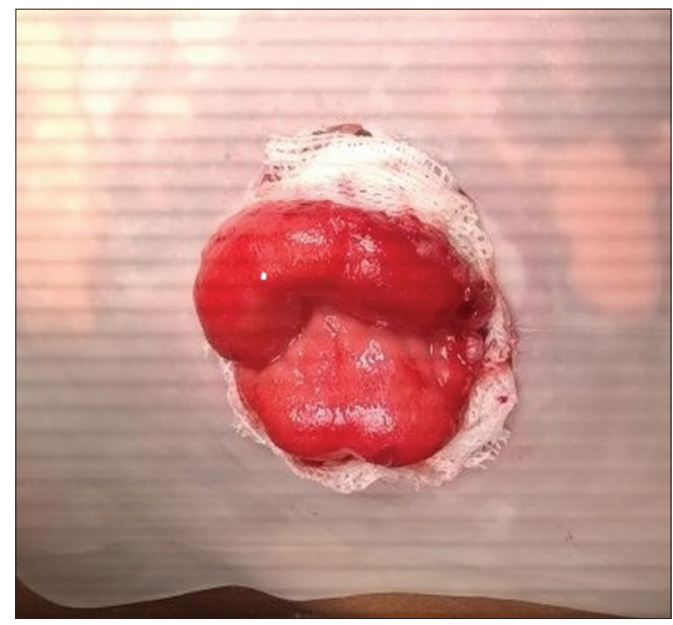

Figure 2 Post-debridement, healthy colostomy

\section{References}

1. Steenvoorde P, Jacobi CE, Van Doorn L, Oskam J. Maggot debridement therapy of infected ulcers: patient and wound factors influencing outcome - a study on 101 patients with 117 wounds. Ann R Coll Surg Engl 2007;89:596-602.

2. Campbell N, Campbell D. A retrospective, quality improvement review of maggot debridement therapy outcomes in a foot and leg ulcer clinic. Ostomy Wound Manage 2014;60:16-25.

3. Mumcuoglu KY. Clinical applications for maggots in wound care. Am J Clin Dermatol 2001;2:219-227. 